УДК 338.1

\title{
E. A. Фархутдинова
}

ФГКОУ ВО «Академия права и управления Федеральной службы исполнения наказаний (Академия ФСИН России)», Рязань, e-mail: farkhutdinovalove@mail.ru

\section{Г. В. Калинина}

ФГКОУ ВО «Академия права и управления Федеральной службы исполнения наказаний (Академия ФСИН России)», Рязань, e-mail: gvkalinina@mail.ru

\section{E. В. Мишанова}

ФГКОУ ВО «Академия права и управления Федеральной службы исполнения наказаний (Академия ФСИН России)», Рязань, e-mail: mev-r@yandex.ru

\section{К ВОПРОСУ ПОВЫШЕНИЯ ЭФФЕКТИВНОСТИ ИСПОЛЬЗОВАНИЯ ОСНОВНЫХ СРЕДСТВ}

Ключевые слова: основные средства, эффективность, фондоотдача, ОАО «РЖД», материальнотехническая база.

В статье по направлению 08.00.05 Экономика и управление народным хозяйством рассматриваются проблемные вопросы анализа эффективности использование основных средств, Железнодорожная отрасль является фондоемкой, объем основных средств постоянно возрастает, на их долю в настоящее время приходится более $80 \%$ по отношению к общей сумме активов. повышение эффективности использования основных средств, позволят повысить рост производительности труда железнодорожного транспорта и соответственно в большей мере удовлетворить потребности в перевозках грузов и пассажиров. Значительные потребление электроэнергии железными дорогами и увеличение энергетической составляющей затрат позволяет считать энергосбережение на железнодорожном транспорте приоритетным направлением уменьшения эксплуатационных затрат. Использование корреляционно-регрессионного аппарата позволило определить зависимость между фондоотдачей и эксплуатационными расходами. Замена счетчиков постоянного тока серии СКВТ-Д621 на электроподвижном составе железных дорог счетчиками серии СКВТ-Ф610 позволит снизить потери по электроэнергии. В статье приводится экономическое обоснование данной замены с расчетом срока окупаемости. Оборудование локомотивов новыми электрическими счетчиками с большим классом точности позволит сократить эксплуатационные расходы Локомотивного депо до 1-2\%, т.к. сократиться разница по потерям электроэнергии. Прогнозное значение эксплуатационных расходов составит 2122663 тыс. руб. Используя уравнение регрессии, прогнозное значение фондоотдачи составит 0,38. Увеличение фондоотдачи свидетельствует о повышении эффективности использования основных средств.

\section{E. A. Farkhutdinova}

Academy of law and management of the Federal penitentiary service

(Academy of the FPIS of Russia), Ryazan, e-mail: farkhutdinovalove@mail.ru

\section{G. V. Kalinina}

Academy of law and management of the Federal penitentiary service

(Academy of the FPIS of Russia), Ryazan, e-mail: gvkalinina@mail.ru

E. V. Mishanova

Academy of law and management of the Federal penitentiary service

(Academy of the FPIS of Russia), Ryazan, e-mail: mev-r@yandex.ru

\section{ON THE ISSUE OF IMPROVING THE EFFICIENCY OF THE USE OF FIXED ASSETS}

Keywords: fixed assets, efficiency, capital return, JSC «Russian Railways», material and technical base.

The article in the direction 08.00.05 Economy and management of the national economy deals with problematic issues of analyzing the effectiveness of the use of fixed assets, the Railway industry is Fundintensive, the volume of fixed assets is constantly increasing, their share currently accounts for more than $80 \%$ in relation to the total amount of assets. increasing the efficiency of using fixed assets will allow increasing the productivity of railway transport and, accordingly, to meet the needs for the transportation of goods and passengers to a greater extent. Significant electricity consumption by Railways and an increase in the energy component of costs makes it possible to consider energy conservation in railway transport as a priority direction for reducing operating costs. The use of a correlation and regression apparatus allowed us to determine the relationship between the return on funds and operating costs. Replacing DC meters of the skvt-D621 series on electric railway rolling stock with meters of the skvt-F610 series will reduce electricity losses. The article provides an economic justification for this replacement with the calculation of the payback 


\section{Введение}

Основные средства в своей совокупности составляют материально-техническую базу и определяют производственную мощность предприятия. Основные средства являются важным фактором хозяйственной деятельности. Эффективное использование основных средств способствует улучшению всех экономических показателей, в том числе увеличение объема выполненных работ, снижение их себестоимости и трудоемкости [1]. Железнодорожная отрасль является фондоемкой, объем основных средств постоянно возрастает, на их долю в настоящее время приходится более $80 \%$ по отношению к общей сумме активов. В составе сооружений на железных дорогах относят металлические мосты, земельное полотно и верхнее строение пути (представляет комплексную конструкцию, которая включает в себя балласт, рельсы, шпалы, промежуточного рельсового скрепления), также учитывают передаточные устройства (кабельные и воздушные высоковольтные линии, контактная сеть). Электровозы и тепловозы, электропоезда и дизельные поезда, грузовые и пассажирские входят в группу транспортных средств [2].

\section{Цель исследования}

Разработка мероприятия, направленных на повышение эффективности использования основных средств, которые позволят повысить рост производительности труда железнодорожного транспорта и соответственно в большей мере удовлетворить потребности в перевозках грузов и пассажиров.

\section{Материалы и методы исследования}

В качестве объекта исследования выступает Эксплуатационное локомотивное депо Рыбное-Сортировочное Дирекции тяги Московской железной дороги - филиал открытого акционерного общества «Российские железные дороги» [3].

\section{Результаты исследования и их обсуждение}

В общей сумме активов организации объекты основных средств занимают наибольший удельный вес в структуре баланса. Результаты деятельности предприятия во многом зависят от техниче- ского уровня основных средств, от эффективности их использования, а также от количества и качества основных средств их стоимости [4].

В период 2016-2018 гг. наблюдается тенденция увеличения стоимости основных средств темп прироста в 2017 г. по сравнению с 2016 г. составил $51 \%$, в 2018 г. по отношению к 2017 г. $29 \%$. Наибольшее увеличение стоимости основных средств в 2018 г. прослеживается по сооружениям и передаточным устройствам и составляет $109 \%$, производственный и хозяйственный инвентарь $11 \%$ или на 690 млн. руб., снижение по отношению к 2017 году наблюдается в части остальных не названных основных средств.

В Эксплуатационном локомотивном депо значительно преобладают транспортные средства в 2018 г. их размер увеличился почти в 2 раза и составляет 1110492 тыс. руб., в 2017 г. -814 700 тыс. руб., в 2016 г. - 5228 18,15 тыс. руб., так как основной вид деятельности организации - грузовые перевозки. Пассивная часть основных фондов составляет $16 \%$. Основная доля стоимости основных фондов приходится на их активную часть $-84 \%$ и в первую очередь на «Транспортные средства». На их долю приходится $77 \%$.

В 2018 г. техническое состояние основных средств улучшилось за счет более интенсивного их обновления. Коэффициент обновления к прошлому году повышен на $0,02 \%$. Рост обновления имущества обусловлен поступлением мощными и прогрессивными основными средствами. В организации коэффициент выбытия отстает от коэффициента обновления. Это свидетельствует о том, что обновление основных средств осуществляется за счет замены старых, изношенных основных средств [5].

Наиболее обобщающим показателем эффективности использования основных фондов является фондорентабельность. К сожалению, не предоставляется возможным рассчитать на примере в структурного подразделения, т.к. Эксплуатационное локомотивное депо не рассчитывает такой показатель, как прибыль. Данный показатель формируется на уровне Открытого Акционерного Общества «Российские железные дороги». Одним из показателей исполь- 
зования основных средств является показатель фондоотдачи. Анализ динамики интенсивности и эффективности использования основных средств ОАО «РЖД» за 2016 - 2018 гг. на основе аналитической таблицы к отчету о движении денежных средств (табл. 1).

Динамика показателей эффективности использования основных средств показывает снижение отдачи в 2018 году по отношению к 2017 году на 14\% от использования основных производственных фондов. Идентичная ситуация наблюдается по отношению к показателю фондоемкости, теперь для единицы продукции, должно использоваться основных средств на $16 \%$ больше. Таким образом, в 2018 г. показатели интенсивности и эффективности использования основных средств снизились по сравнению с прошлыми годами.

Основная деятельность Эксплуатационное локомотивное депо РыбноеСортировочное включает обеспечение грузовых поездов тяговым подвижным составом (тепловозы, электровозы). В силу специфики своей деятельности ТЧЭ-38 является основным потребителем электрической энергии, т.к. большинство локомотивов, стоящих на балансе депо осуществляют движение по электрофицированому участку. Доля потребления электрической энергии от общих эксплуатационных расходов депо составляет $41 \%$. Значительные потребление электроэнергии железными дорогами и увеличение энергетической составляющей затрат позволяет считать энергосбережение на железнодорожном транспорте приоритетным направлением уменьшения эксплуатационных затрат. Для технического учета расхода энергии и оценки эффективности мероприятий по энергосбережению и нормированию на участке или в депо необходимо точное измерение расхода электроэнергии на электровозах переменного тока.

С каждым годом особую значимость приобретают вопросы энергосбережения и эффективного использования электроэнергии, из-за роста цен на энергетические ресурсы обостряется проблемы экономии топливно-энергетических ресурсов [6]. На железнодорожном транспорте, в частности, одной из основных проблем является снижение потерь электрической энергии, в системе тягового электроснабжения электрифицированных железных дорог.

На электропотери могут оказывать влияние эксплуатационные показатели, такие как: участковая и техническая скорость, средний вес поезда, количество остановок вне графика и другие, организационно-техническое обеспечение процесса перевозок. Следовательно, необходимо оценить влияние устройств электроснабжения на эксплуатационные расходы в части электроэнергии, а также как замена приборов учета электроэнергии на приборы учета более высокого класса точности повлияет на деятельность Эксплуатационного Локомотивного депо Рыбное-Сортировочное.

\section{Таблица 1}

Динамика интенсивности и эффективности использования основных средств*

\begin{tabular}{|l|c|c|c|c|c|}
\hline \multicolumn{1}{|c|}{ Показатели } & 2016 г. & 2017 г. & 2018 г. & \multicolumn{2}{|c|}{ Темп прироста, \% } \\
\cline { 4 - 6 } & & & & 2017 г. & $\begin{array}{c}2018 \text { г. } \\
\text { к 2016 г. } 2017 \text { г. }\end{array}$ \\
\hline $\begin{array}{l}\text { Денежные поступления от текущих операций, } \\
\text { тыс. руб. }\end{array}$ & 272699,79 & 375698,23 & 446876,19 & 37,77 & 18,95 \\
\hline $\begin{array}{l}\text { Среднегодовая стоимость основных фондов, } \\
\text { тыс. руб. }\end{array}$ & 675564,42 & 921522,51 & 1275224,61 & 36,41 & 38,38 \\
\hline $\begin{array}{l}\text { в том числе активная часть основных фондов, } \\
\text { тыс. руб. }\end{array}$ & 540451,54 & 746433,23 & 1021084,18 & 38,11 & 36,80 \\
\hline Удельный вес активной части,\% & 80,00 & 81,00 & 80,07 & 1,25 & $-1,15$ \\
\hline Фондоотдача активной части & 0,50 & 0,50 & 0,44 & $-0,25$ & $-13,05$ \\
\hline Фондоотдача & 0,42 & 0,41 & 0,35 & $-3,45$ & $-14,05$ \\
\hline Фондоемкость & 2,37 & 2,45 & 2,85 & 3,57 & 16,34 \\
\hline
\end{tabular}

П р и м е ч а и е . *Российские железные дороги - Режим доступа: http://www.rzd.ru. 
На показатель фондоотдачи оказывает влияние ряд показателей деятельности предприятия. С точки зрения управления важно изучить характер взаимосвязи между показателями. Очевидно, что чем теснее связь, тем легче управление системами и точнее принимаемые решения. Исследование связи между показателями и ее установление осуществляется с помощью корреляционного и регрессионного анализа. Зависимость между фондоотдачей и эксплуатационными расходами является стохастической поэтому для ее исследования используем корреляционный и регрессионный анализы [7].

Коэффициенты парной корреляции позволяют оценить взаимосвязь между выбранными показателями и возможность их использования для построения регрессионной модели. Взаимосвязь между выбранными показателями является сильной и обратной, что говорит об уменьшении фондоотдачи предприятия с ростом эксплуатационных расходов $(\mathrm{Rxy}=-0,73)$. Следовательно, данные показатели могут использоваться для построения регрессионной модели зависимости фондоотдачи и эксплуатационных расходов. Результатами регрессионного анализа явились таблицы: корреляционная статистика, дисперсионный анализ, регрессионная статистика, получены в следствии использования надстройки MS Excel Анализ данных [8].

Коэффициент детерминации показывает, что $53 \%$ вариации фондоотдачи предприятия находится под воздействием фактора эксплуатационных расходов.

Проверка значимости уравнения регрессии была проведена на основе $\mathrm{F}$ критерия Фишера. По данным дисперсионного анализа Fрасч $=6,77$. Табличное значение $\mathrm{F}$ - критерия при доверительной вероятности $v_{1}=1$ и $v_{2}=6$ Fтабл $=5,99$. Так как Fрасч > Fтабл, следовательно, уравнение регрессии следует признать адекватным [9].

Значимость коэффициента уравнения регрессии а была оценена с помощью t-критерия Стьюдента. По регрессионной статистики $\mathrm{t}_{\mathrm{a} 1}=2,60$. Табличное значение t-критерия при уравнении значимости $5 \%$ и степенях свободы 7 составляет 2,45 . Так как $\mathrm{t}_{\text {рас }}>\mathrm{t}_{\text {табл }}$, то коэффициент $\mathrm{a}_{1}$ - существенен, то есть значим.
На основании регрессионной статистики составляем уравнение регрессии, описывающее зависимость фондоотдачи от эксплуатационных расходов: $\mathrm{Y}=0,64+1,1826 \mathrm{E}-07 \mathrm{X}$.

В настоящее время в Эксплуатационном локомотивном депо расчет электроэнергии ведется по двум видам счетчиков. Электросчетчик постоянного тока серии СКВТ-Д621 предназначен для учета и измерений электроэнергии постоянного тока на электроподвижном составе железных дорог. Класс точности 2,5, средний срок службы 10 лет. Данный счетчик снабжает практически все электровозы. Счетчик СКВТ-Д621 снят с производства, поэтому в случае неисправности подвергается ремонту, обновление счетчиков данной серии невозможно.

Небольшая часть локомотивов оборудована электросчетчиками с большей точностью СКВТ-Ф610, срок полезного использования составляет 15 лет, класс точности 1, чем меньше цифра обозначения на лицевой панели электросчетчика, тем выше уровень класса. Стоимость счетчика 23851 руб.

За декабрь 2018 года процент потерь в Эксплуатационном локомотивном депо Рыбное-Сортировочное по электроэнергии составил $18,55 \%$, весь расход на весь парк электровозов серии ВЛ10У с учетом потерь равен 13 999,41 тыс. кВч*ч. Сумма потерь по электроэнергии составила 2 607,97 тыс. кВт*ч.

Общее количество локомотивов, задействованных в декабре 2018 года, составляет 44 электровоза. Из них счетчиками СКВТ-Ф610, имеющих больший класс точности, оборудовано 7 электровозов серии ВЛ10У, 37 электровозов этой же серии оборудовано электросчетчика СКВТ-Д621. В таблице представлена сумма топливно-энергетических расходов и объем работы. Топливноэнергетические расходы на тягу поездов представлены в табл. 2.

Удельный расход электроэнергии кВТ $\times$ ч $=$ уд.вес $($ СКВТ-Ф610) / (уд.вес СКВТ-Д621 $)=(88,60 / 84,44)=1,049$ кВт ×ч.

Расход электроэнергии с применением счетчиков серии СКВТ-Ф610 с учетом потерь составили 12 143,97 тыс. кВт×ч, а по показаниям счетчика 9896 тыс. кВт×ч. В среднем на один электрово3, оборудованных счетчиками серии 
СКВТ-Ф610, потери по электроэнергии принимают значение 60,755 кВт×ч. Общая сумма потерь по электроэнергии в расчете, что на 1 кВт приходится 4,22 руб., составит $2247,97 \times 4,22=9486$, 43 тыс. руб., в связи с этим неоправданно возрастают эксплуатационное расходы ТЧЭ-38. рудования всех локомотивов новыми счетчиками, в общей сумме снижение эксплуатационных расходов по потери электроэнергии в среднем произойдет на 72,07 тыс. руб. в месяц.

Срок окупаемости установленных счетчиков составит: 882 484/72 $070=$ $=12$ месяцев. Стоит отметить, что в расчет

Таблица 2

Топливно-энергетические расходы на тягу поездов

\begin{tabular}{|c|c|c|c|c|c|}
\hline $\begin{array}{c}\text { Серия } \\
\text { ТПС }\end{array}$ & $\begin{array}{c}\text { Количество, } \\
\text { шт. }\end{array}$ & $\begin{array}{c}\text { Серия элек- } \\
\text { тросчетчика }\end{array}$ & $\begin{array}{c}\text { Работа, } 10 \text { тыс. } \\
\text { т-км брутто }\end{array}$ & $\begin{array}{c}\text { Расход ТЭР, } \\
\text { тыс.кВт*ч }\end{array}$ & $\begin{array}{c}\text { Удельный расход электро- } \\
\text { энергии, кВт*ч/ 10 тыс. т-км } \\
\text { брутто }\end{array}$ \\
\hline ВЛ10У & 7 & СКВТ-Ф610 & 17057 & 1511 & 88,60 \\
\hline ВЛ10У & 37 & СКВТ-Д621 & 117118 & 9896 & 84,44 \\
\hline
\end{tabular}

Расход электроэнергии с применением электросчетчиков с большей точностью класса составляет 1511 тыс. кВт×ч. С потерями $(1511 \times 100) /(100-$ $18,511)=1854,23$ тыс. кВт×ч - полученное значение учитывается счетчиками, установленными на тяговых подстанциях. Разница между показаниями счетчиков тяговой подстанции и электросчетчиками локомотивов образует сумму потерь по электроэнергии. Сумма потерь составит $1855,44-1511=343,23$ тыс. кВт $\times ч-$ на 7 локомотивов, оборудованных счетчиками с большей точностью.

На 1 локомотив потери составили: 344/7 = 49,2 тыс. кВт×ч.

Снижение условных потерь за счет счетчиков нового класса: 49,2 (100$(100 / 1,049)=2,31$ тыс. кВт×ч.

Снижение потерь электросети для отдельно взятого локомотива составит: 2,31×4,22 = 9,739 тыс. руб. (4,22 руб. приходится на 1 кВТ×ч), а на общее число электровозов 9,739×7 = 68,17 тыс. руб.

Это приведет к перераспределению небаланса между прогнозным потреблением в границах обращения [10].

За счет увеличения класса точности прибора учета электроэнергии на одном локомотиве перераспределение потерь в контактной сети снизится на $20 \%$ от повышения учтенного расхода электроэнергии, что составит 0,462 тыс. кВт×ч в месяц на сумму 1,948 тыс. рублей.

Для снабжения электровозов серии ВЛ10У счетчиками СКВТ-Ф610 необходимо 882487 рублей. В случае обо- не включалась сумма установки прибора учета электроэнергии, а также возникшие расходы на заработную плату работнику, производящего монтаж оборудования, социальные отчисления [11].

\section{Заключение}

С целью повышения эффективности использования основных средств Эксплуатационного локомотивного депо Рыбное-Сортировочное предлагается оборудовать локомотивы новыми электрическими счетчиками с большей точностью, что позволит сократить эксплуатационные расходы Локомотивного депо на электроэнергию. Прибор по учету топливно-энергетических ресурсов позволит значительно повысить класс точности измерения расхода потребляемой электроэнергии на электровозе.

Оборудование локомотивов новыми электрическими счетчиками с большим классом точности позволит сократить эксплуатационные расходы Локомотивного депо до 1-2\%, т.к. сократиться разница по потерям электроэнергии. Прогнозное значение эксплуатационных расходов составит 2122663 тыс. руб. Используя уравнение регрессии, прогнозное значение фондоотдачи составит 0,38. Увеличение фондоотдачи свидетельствует о повышении эффективности использования основных средств.

Реализация предложенного мероприятия позволит эффективно использовать 
имеющиеся оборудования за счет снижения его простоев, своевременного ремонта, замены изношенных деталей.

Несмотря на положительную работу Эксплуатационного депо в 2018 г., следует контролировать динамику обновления активной части основных фондов, т.к. использование устаревшей техники снижает эффективность производства, поскольку она требует больших затрат на ее текущее содержание и ремонт. Это позволит более рационально использовать основные фонды на предприятиях OAО «РЖД».

\section{Библиографический список}

1. Калинина Г.В. К вопросу повышения эффективности использования основных средств в сельскохозяйственных предприятиях // Сб.: Вклад университетской аграрной науки в инновационное развитие агропромышленного комплекса: матер. 70-й междунар. научно-практич. Конфер. - Рязань: Рязанский государственный агротехнологический университет им. П.А. Костычева, 2019. С. $259-263$.

2. Иванов А.В. Анализ деятельности компании ОАО «РЖД» в условиях кризиса // Наука XXI века: актуальные направления развития, 2016. - № 1-1. - С. 173-176.

3. Российские железные дороги - Режим доступа: http://www.rzd.ru/ (дата обращения: 28.02.2020).

4. Ушачев И.Г., Аношина Ю.Ф., Жукова О.В., Мамедова Н.А., Ерохина Е.И., Кирова И.В., Курочкина Е.Н., Пономарева Е.В. Экономика России. Актуальные проблемы и вызовы / М.: Научный консультант, 2018 - 168 с.

5. Курочкина Е.Н., Калинина Г.В. Оценка динамики состояния материально-технической базы сельскохозяйственных предприятий // Сб.: Потенциал науки и современного образования в решении приоритетных задач АПК и лесного хозяйства: матер. юбил. национ. научно-практич. конфер. - Рязань: Рязанский государственный агротехнологический университет им. П.А. Костычева, 2019. - C. 167-172

6. Вахрушева Н.А. Пути повышения эффективности использования основных средств // Экономические науки, 2019. - № 177. - С. 46-50.

7. Фефилова О.С. Повышение экономической эффективности использования основных средств путем внедрения нового оборудования // Инженерные кадры - будущее инновационной экономики России, 2018. - № 6. - С. 157-160.

8. Морозова Л.А., Черкашина Л.В. Оценка качества информационных систем // Сб.: Потребительский рынок: качество и безопасность товаров и услуг: матер. национ. научно-практич. конфер. - Рязань: Рязанский государственный агротехнологический университет им. П.А. Костычева, 2019. - C. 176-181.

9. Грекова В.А., Волошина Е.И. Инструментарий анализа эффективности использования основных средств в аудите // Научный вестник: финансы, банки, инвестиции, 2019. - № 3 (48). - С. $196-203$.

10. Кармацких Д.М., Рознина Н.В., Карпова М.В. Основные средства как неотъемлемая часть производственно-хозяйственной деятельности и эффективность их использования // Актуальные вопросы современной экономики, 2019. - № 5. - С. 405-411.

11. Калинина Г.В., Мишанова Е.В. Взаимосвязь бухгалтерского и налогового учета основных средств на современном этапе // Вестник Алтайской академии экономики и права. - 2019. - № 4. - С. $49-54$. 